\title{
Editorial
}

\section{Vitamin D status: to be considered in heart failure patients}

\section{S Y Ali}

Recent data on the world wide high prevalence of vitamin D (Vit. D) deficiency and identification of Vit. D receptor (VDR) expression in almost all human cells raised public health interest in vitamin D. Vitamin D is well known as a major regulator of calcium and bone metabolism, and its supplementation is an established treatment for patients suffering from musculoskeletal diseases ${ }^{1,2}$. Furthermore it is increasingly recognized that Vit. D and its related mineral metabolism may also play a crucial role in overall and cardiovascular health ${ }^{1-7}$. Two prospective studies published in The European Journal of Heart Failure reported that low Vit. D status is highly prevalent among heart failure patients and indicates an increased risk of mortality $^{8-9}$. Liu et $\mathrm{al}^{8}$ examined 548 heart failure patients and found that after a mean follow-up of 18 months; low and base line 25-hydroxyvitamin D [25(OH)D] plasma concentrations were associated with significantly increased risk of all cause mortality.

Expression of VDR and key enzymes of Vit. D metabolism in both the heart and the arterial vessels argue for an important role of Vit. D in the cardiovascular system $^{3,4}$. Molecular pathways for Vit. D induced renin suppression have already been clarified and this is in line with the negative association between $25(\mathrm{OH}) \mathrm{D}$ and plasma renin activity observed by Liu et $\mathrm{al}^{8}$. In the same work C-reactive protein was significantly increased in patients with a poor Vit. D status ${ }^{8}$. This may reflect antiinflammatory actions of Vit. D which have been observed in previous studies including a randomized Controlled Trail (RCT) of heart failure patients ${ }^{3,4}$. In addition vitamin $\mathrm{D}$ metabolites have been shown to exert various direct effects on cardiomyocytes including antihypertrophic actions, regulation of extra cellular matrix turnover, and modulation of contractility ${ }^{3,4}$. This latter effect seems to be mainly driven by regulation of cardiac calcium flux ${ }^{3,4}$. Deleterious consequences of Vit. D deficiency on the cardio-vascular system may also be mediated by parathyroid hormone (PTH). Vit. D deficiency contributes to, low serum calcium levels which in turn stimulates PTH secretion in order to maintain serum Calcium within physiological ranges. Schierbeck et al reported that PTH serum concentrations above the median are independent predictor of mortality ${ }^{9}$. This supports previous studies, documenting association of PTH with mortality, cardiovascular events and heart failure hospitalization ${ }^{3,4,12,13}$. Poor Vit. D status has also been related to classic cardiovascular risk factors such as arterial hypertension, Diabetes mellitus, and chronic kidney disease $(\mathrm{CKD})^{1-4,14}$.

Interventional studies of the effects of Vit. D supplementation on myocardial structure and functions are sparse and are largely limited by small sample sizes $^{3,4}$. Some of the reported data show improved myocardial function and reduced myocardial hypertrophy after Vit. D treatment ${ }^{3,4}$. Studies show that most of the heart failure patients have $25(\mathrm{OH}) \mathrm{D}$ levels below the normal range at least $75 \mathrm{nmol} / \mathrm{L}^{1,3,4,8,9}$. Furthermore Vit. D therapy is relatively easy, cheap and Dr. Sk. Yunus Ali, Assistant Professor Department of Cardiology, FMC. Phone:+88-0171-1208966

Email: drskyunusali@gmail.com safe $^{3,4,6}$. Daily Vit. D supplementation of 1000 IU increases $25(\mathrm{OH}) \mathrm{D}$ concentrations by $25 \mathrm{n} \mathrm{mol} / \mathrm{L}^{4,6}$. There are no respective data for heart failure patients but a meta- analysis of randomized controlled trials that largely included frail elderly patients, showed that Vit. D supplementations significantly reduced all mortality by $7 \%$, compared with placebo ${ }^{15}$. Considering the proposed multiple health benefits of Vit. D, we believe that it is reasonable to aim for an adequate Vit. D status. Nevertheless despite accumulating data on the association of Vit. D deficiency with heart disease and related increased mortality, we still need more results from large randomized controlled trials before introducing general recommendations for the treatment of Vit. D deficiency in the heart failure patients.

\section{References}

1. Holick MF. Vitamin D deficiency. N Engl J Med. 2007; 357:281.

2. Souberbielle JC, Body JJ, Lappe JM, Plebani M, Shoenfeld Y, Wang $\mathrm{TJ}$, et al. Vitamin D and musculoskeletal health, cardiovascula disease, autoimmunity and cancer. Recommendations for clinical practice. Autoimmun Rev. 2010; 9:709-715.

3. Cozzolino M, Ketteler M, Zehnder D. The vitamin D system: a crosstalk between the heart and kidney. Eur J Heart Fail. 2010; 12:1031-1041.

4. Pilz S, Tomaschitz S, Drechsler C, Dekker JM, Marz W. Vitamin $\mathrm{D}$ deficiency and myocardial diseases. Mol Nutr Food Res. 2010; 54:1103-1113.

5. Zitterman A, Schleithoff SS, Gotting C, Dronow O, Fuchs U, Khun J, Kleesiek K, Tenderich G, Koerfer R. Poor outcome in end-stage heart failure patients with low circulating calcitriol levels. Eur J Heart Fail. 2008; 10:321-327.

6. Pilz S, Tomaschitz A, Drechsler C, Zittermann A, Dekker JM, Marz W. Vitamin D supplementation: a promising approach for the prevention and treatment of strokes. Curr Drug Target 2011; 12:88-96.

7. Dhingra R, Gona P, Benjamin EJ, Wang TJ, Aragam J, D'Agostino $\mathrm{Sr} \mathrm{RB}$, et al. Relations of serum phosphorus levels to echocardiographic left ventricular mass and incidence of heart failure in the community. Eur J Heart Fail. 2010; 12:812-818.

8. Liu LC, Voors AA, van Veldhuisen DJ, van der Veer E, Belonje AM, Szymanski MK, et al. Vitamin D status and outcomes in heart failure patients. Eur J Heart Fail. 2011; 13:619-625.

9. Schierbeck LL, Jensen TS, Bang U, Jensen G, Kobler L, Jensen $\mathrm{JE}$. Parathyroid hormone and vitamin D-markers for Fail. 2011; 13:626-632.

10.Pilz S, Marz W, Wellnitz B, Seelhorst U, Fahrleitner-Pammer A Dimai HP, et al. Association of vitamin D deficiency with heart failure and sudden cardiac death in a large cross-sectional study of patients referred for coronary angiography. J Clin Endocrinol Metab. 2008; 93:3927-3935.

11.Drechsler C, Pilz S, Obermayer-pietsch B, Verduijn M, Tomaschitz A, Krane V, et al. Vitamin D deficiency is associated with sudden cardiac death, combined cardiovascular events and mortality in haemodialysis patients. Eur Heart J. 2010; 31:2253-2261.

12.Hagstrom E, Ingelsson E, Sundstrom J, Hellman P, Larsson TE, Berglund L, et al. Plasma parathyroid hormone and risk of congestive heart failure in community. Eur J Heart Fail. 2010; 12:1186-1192.

13.Pilz S, Tomaschitz A, Drechsler C, Ritz E, Boehm BO, Grammer TB, Marz W. Parathyroid hormone level is associated with mortality and cardiovascular events in patients undergoing coronary angiography. Eur Heart J. 2010; 31:1591-1598.

14.Pilz S, Tomaschitz A. Role of vitamin D in arterial hypertension. Expert Rev Cardiovasc Ther. 2010; 8:1599-1608.

15.Autier P, Gandini S. Vitamin D supplementation and total mortality: a meta analysis of randomized controlled trails. Arch Intern Med. 2007; 167:1730-1737. 